\title{
Uso do planejamento experimental visando avaliar o efeito da razão $C / N$ e N/P na cinética de crescimento de uma cianobactéria
}

A Aphanothece microscópica Nägeli é uma cianobactéria com capacidade de crescer em efluentes provenientes de atividades industriais, explorando seus mecanismos auxiliares como a respiração para remover os nutrientes dos efluentes e gerar bioprodutos com valores agregados. 0 presente trabalho visa contribuir para a otimização da razão $\mathrm{C} / \mathrm{N}$ e N/P no efluente de laticínio permitindo avaliar o efeito destes elementos na cinética de crescimento da Aphanothece microscópica Nägeli. Os cultivos da cianobactéria foram conduzidos no efluente de laticínio em um biorreator heterotrófico, sob as condições de concentração celular inicial de $200 \mathrm{mg}$. L-1, pH inicial 7,6, temperatura de 30 C, aeração contínua e ausência de luminosidade. Realizou-se um planejamento experimental fatorial (32), com os fatores: $\mathrm{C} / \mathrm{N}(20,40$, e 60$)$ e N/P $(5,10,15)$. O ajuste das razões C/N e N/P foi realizado tomando como base as relações DQO/N-NTK e N-NTK/P-PO4-3 previamente determinadas no efluente. A razão $\mathrm{C} / \mathrm{N}$ foi ajustada com glicose e a N/P com fosfato dissódico. O cultivo da Aphanothece no efluente com as razões $\mathrm{C} / \mathrm{N} 20$ e N/P 10, obtiveram os melhores valores cinéticos com concentração celular máxima de $1045 \mathrm{mg}$. L-1, velocidade máxima específica de crescimento de $0,250 \mathrm{~h}-1$, tempo de geração de $2,77 \mathrm{~h}$ e tempo de batelada para atingir a máxima concentração celular de $6 \mathrm{~h}$.

Palavras-chave: Aphanothece microscópica Nägeli; $\mathrm{C} / \mathrm{N} ; \mathrm{N} / \mathrm{P}$.

\section{Use of experimental planning to evaluate the effect of the $C / N$ and $N / P$ ratio on the growth kinetics of a cyanobacterium}

\begin{abstract}
Aphanothece microscópica Nägeli is a cyanobacterium with the ability to grow in effluents originated from industrial activities by exploiting its auxiliary mechanisms such as respiration to remove nutrients from the effluents and to generate bioproducts with aggregated values. The present work aims to contribute to the optimization of the $\mathrm{C} / \mathrm{N}$ and N/P ratio in the dairy effluent, allowing the evaluation of the effect of these elements on the growth kinetics of Aphanothece microscópica Nägeli. The cultivation of the cyanobacteria were conducted in the dairy effluent in a heterotrophic bioreactor under initial cell concentration conditions of $200 \mathrm{mg} . \mathrm{L}-1$, initial pH 7.6, temperature of $30^{\circ} \mathrm{C}$, continuous aeration and absence of light. A factorial experimental design (32) was used with the following factors: $\mathrm{C} / \mathrm{N}(20,40$, and 60$)$ and N/P $(5,10,15)$. The $\mathrm{C} / \mathrm{N}$ and N/P ratios were adjusted based on the previously determined COD/N-NTK and N-NTK/PPO4-3 ratios in the effluent. The $\mathrm{C} / \mathrm{N}$ ratio was adjusted with glucose and $\mathrm{N} / \mathrm{P}$ with disodium phosphate. The cultivation of Aphanothece in the effluent with the $\mathrm{C} / \mathrm{N} 20$ and N/P 10 ratios obtained the best kinetic values with a maximum cell concentration of $1045 \mathrm{mg}$. L-1, maximum specific growth velocity of $0.250 \mathrm{~h}-1$, generation time of $2.77 \mathrm{~h}$ and batch time to reach the maximum cell concentration of $6 \mathrm{~h}$.
\end{abstract}

Keywords: Aphanothece microscópica Nägeli; C/N; N/P.

Topic: Desenvolvimento, Sustentabilidade e Meio Ambiente

Reviewed anonymously in the process of blind peer.
Received: $10 / 08 / 2018$

Approved: 24/09/2018
Thais Magalhães Possa (D)

Universidade Federal de Pelotas, Brasil

http://lattes.cnpq.br/1526541693184849

http://orcid.org/0000-0001-5221-8755

thaispossa03@gmail.com

Gustavo Holz Bracher (iD

Universidade Federal de Pelotas, Brasil

http://lattes.cnpq.br/1962820275069667

http://orcid.org/0000-0003-2669-519X

gustavohbracher@gmail.com

Adriana Gonçalves da Silva Manetti

Universidade Federal de Pelotas, Brasil

http://lattes.cnpq.br/0103882542744811

http://orcid.org/0000-0002-3137-4078

didialimentos@yahoo.com.br

\author{
Vanessa Sacramento Cerqueira 10 \\ Universidade Federal de Pelotas, Brasil \\ http://lattes.cnpq.br/5269420717974016 \\ http://orcid.org/0000-0003-2604-7846 \\ vanescerqueira@yahoo.com.br \\ Claudia Fernanda Lemons Silva (ib \\ Universidade Federal de Pelotas, Brasil \\ http://lattes.cnpq.br/8387065724345198 \\ http://orcid.org/0000-0001-7187-7000 \\ lemonsclau@gmail.com
}

Referencing this:

POSSA, T. M.; BRACHER, G. H.; MANETTI, A. G. S.; CERQUEIRA, V. S.; SILVA, C. F. L.. Uso do planejamento experimental visando avaliar o efeito da razão $\mathrm{C} / \mathrm{N}$ e N/P na cinética de crescimento de uma cianobactéria. Revista Ibero Americana de Ciências Ambientais, v.9, n.7, p.224-235, 2018. DOI: http://doi.org/10.6008/CBPC21796858.2018.007.0020 


\section{INTRODUÇÃO}

As microalgas possuem uma diversidade de produtos bioquímicos em sua constituição como proteínas, ácidos graxos poli-insaturados, vitaminas e pigmentos fotossintéticos. Destes pigmentos fotossintéticos, os mais importantes são as clorofilas, carotenóides e ficobiliproteínas que compõem exclusivamente as estruturas de algas vermelhas, cryptomonas e cianobactérias (STREIT et al., 2017). Em outras palavras, o termo genérico microalga inclui microrganismos de dois grandes grupos: Cianobactérias, seres procariontes e unicelulares que possuem capacidade fotossintética e organismos eucarióticos, como as algas verdes-azuis (HOMIAK, 2014; MATA et al., 2010).

As cianobactérias apresentam um metabolismo capaz de induzir a produção de compostos a partir de biomassa microalgal, podendo esses ser utilizados na produção de biocombustíveis ou na produção de insumos para alimentação animal (ANGELO et al., 2015). Elas possuem as necessidades mais simples de nutrição existentes, proliferando-se em qualquer ambiente que proporcione condições semelhantes às de seus habitats naturais, que devem ter luz solar possibilitando o desenvolvimento de suas atividades e o crescimento celular (NOBRE et al., 2013).

O crescente interesse em tecnologias limpas, como as que envolvem culturas de microalgas, vem se destacando no tratamento de efluentes agroindustriais. A aplicação destes microrganismos demonstra ser uma alternativa sustentável já que permite a fixação do dióxido de carbono atmosférico e inclusive, a remoção de nutrientes, metais pesados e patógenos através da absorção do oxigênio (ANSILAGO et al., 2016).

Determinadas espécies como Chlorella sp., Scenedesmus sp. e Aphanothece sp. possuem a capacidade de crescer heterotroficamente no escuro e substituem a fixação do $\mathrm{CO}_{2}$ atmosférico, natural de acontecer em culturas autotrófica, pelo uso de um substrato orgânico dissolvido no meio de cultura atuando como fonte de carbono e energia (BASTOS et al., 2015; MEDINA et al., 2016; PEREZ-GARCIA et al., 2011).

A cianobactéria Aphanothece microscópica Nägeli apresenta comum ocorrência nos corpos hídricos adjacentes à cidade de Rio Grande, RS, Brasil, e sua utilização vem sendo crescente no âmbito de tratamento de águas residuárias (BASTOS et al., 2015; VIEIRA et al., 2012; ZEPKA et al., 2010). Entretanto, para obter as melhores condições que favoreçam o crescimento celular e a biossíntese de bioprodutos, fatores nutricionais e ambientais devem ser controlados (HEREDIA-ARROYO et al., 2010; VIEIRA et al., 2012).

De acordo com Queiroz et al. (2002), concentrações de carbono e nitrogênio balanceadas em uma relação C/N 20 são mais requeridos para o crescimento de microrganismos. Além do tipo e concentração da fonte de carbono no meio de cultura, fontes de nitrogênio e fósforo têm se mostrado fator chave na regulação da produtividade das cianobactérias (BASTOS et al., 2017; MUTHURAJ et al., 2014; PALABHANVI et al., 2014).

Dentre os nutrientes em suas diferentes formas que podem limitar o crescimento microbiano e consequentemente, a produção de derivados químicos renováveis a partir da síntese de pigmentos e proteínas, destacam-se o nitrogênio (RAJOKA et al., 2006). A maior parte do nitrogênio está em suas formas 
inorgânicas (nitrato, nitrito e amônio) e orgânicas dissolvidas, como por exemplo, ureia, aminoácidos e peptídeos (MURO-PASTOR et al., 2003).

Entretanto, a amônia que é assimilada pela via glutamina sintetase (GS) ciclo sintetase-glutamato (GOGAT) é o elemento mais requerido pelas cianobactérias, se comparado com os outros íons, pois está diretamente relacionado a assimilação de outras fontes de nitrogênio (MURO-PASTOR et al., 2003). Por isso, no final da reação enzimática, as outras formas de nitrogênio inorgânico são reduzidas a amônia para serem incorporadas ao fluido intracelular (CAl et al., 2013; LI et al., 2011).

Em meios contendo fósforo, o nutriente é capaz de atrair outros elementos químicos como cálcio e ferro, causando a precipitação química. Embora contenha 1\% de fósforo na biomassa das microalgas, tornase este essencial para o processo de absorção de nutrientes e desenvolvimento das cianobactérias (CAl et al., 2013).

Considerando a importância destes elementos, uma possível diminuição das concentrações dos compostos nitrogenados e fosforados no meio de cultura provoca flutuações nas razões $\mathrm{C} / \mathrm{N}$ e N/P, afetando a capacidade de sobrevivência das cianobactérias (XIN et al., 2010). De acordo com Pearson (1990), a relação ótima entre os nutrientes nitrogenados e fosforados é de 10 a $16 \mathrm{~N}$ para cada $\mathrm{P}$, a qual origina condições favoráveis para o desenvolvimento de florações de cianobactérias. Neste contexto, o presente estudo visa contribuir para a otimização da razão C/N e N/P no efluente de laticínio permitindo avaliar o efeito destes elementos na cinética de crescimento de Aphanothece microscópica Nägeli.

\section{METODOLOGIA}

\section{Obtenção do efluente}

A água residuária do processamento de laticínios foi utilizada como meio de cultivo. O efluente foi obtido em uma indústria de processamento de produtos lácteos (Pelotas, RS), coletado na saída do tanque de equalização da estação de tratamento de efluentes por um período de 6 meses. As amostras foram transportadas em garrafas de polietileno para o Laboratório da Agência da Lagoa Mirim e congeladas a $-18^{\circ} \mathrm{C}$. O efluente foi caracterizado quanto ao $\mathrm{pH}$, demanda química de oxigênio (DQO), nitrogênio total Kjeldahl ( $\mathrm{N}$ NTK), P-PO ${ }_{4}^{-3}$ : fósforo total dissolvido e sólidos suspensos (SS). As análises foram realizadas segundo os procedimentos descritos em Standard Methods para análise de águas e efluentes (APHA, 2005). As razões $\mathrm{C} / \mathrm{N}$ e N/P foram determinadas em função das concentrações de DQO, N-NTK e P-PO ${ }_{4}^{-3}$ presentes no efluente, conforme indicado por Hornes et al. (2004).

\section{Preparo do inóculo}

Suspensões de Aphanothece microscópica Nägeli (RSMan92), cedidas pela Unidade de Cianobactérias da Universidade Federal do Rio Grande, isoladas do estuário da cidade de Rio Grande, RS, Brasil, foram cultivadas e mantidas em meio BG-11 (Braun-Grunow medium) conforme indicado por Rippka et al. (1979). As culturas foram mantidas a 2 klux com fotoperíodo de 12 h, 25ㄷ e pH 7,6 (QUEIROZ et al., 
2004). O cultivo foi realizado em garrafa de polietileno em câmara otimizada quanto à luz e temperatura. Foram utilizadas lâmpadas fluorescentes com intensidade luminosa e temperatura controlada.

O meio BG-11 é composto por $\mathrm{K}_{2} \mathrm{HPO}_{4}, 3 \mathrm{H}_{2} \mathrm{O}\left(0,04 \mathrm{~g} . \mathrm{L}^{-1}\right), \mathrm{MgSO}_{4} .7 \mathrm{H}_{2} \mathrm{O}\left(0,075 \mathrm{~g} . \mathrm{L}^{-1}\right), \mathrm{NaCO}_{3}\left(2 \mathrm{~g} . \mathrm{L}^{-1}\right)$, $\mathrm{NaNO}_{3}\left(1,5 \mathrm{~g} \cdot \mathrm{L}^{-1}\right)$, EDTA $\left(0,001 \mathrm{~g} \cdot \mathrm{L}^{-1}\right), \mathrm{HBO}_{3}\left(2,86 \mathrm{~g} \cdot \mathrm{L}^{-1}\right), \mathrm{MnCl}_{2} \cdot 4 \mathrm{H}_{2} \mathrm{O}\left(1,81 \mathrm{~g} \cdot \mathrm{L}^{-1}\right), \mathrm{ZnSO}_{4} \cdot 7 \mathrm{H}_{2} \mathrm{O}\left(0,222 \mathrm{~g} \cdot \mathrm{L}^{-1}\right)$, $\mathrm{Na}_{2} \mathrm{MoO}_{4} \cdot 2 \mathrm{H}_{2} \mathrm{O}\left(0,39\right.$ g. $\left.\mathrm{L}^{-1}\right), \mathrm{CuSO}_{4} \cdot 5 \mathrm{H}_{2} \mathrm{O}\left(0,079\right.$ g. $\left.\mathrm{L}^{-1}\right), \mathrm{CoCl}_{2} \cdot 6 \mathrm{H}_{2} \mathrm{O}\left(0,040\right.$ g. $\left.\mathrm{L}^{-1}\right), \mathrm{C}_{6} \mathrm{H}_{8} \mathrm{O}_{7}\left(0,006{\mathrm{~g} . \mathrm{L}^{-1}}^{-1}\right.$ e $\mathrm{FeC}_{6} \mathrm{H}_{5} \mathrm{O}_{7}$ $\left(\mathrm{NH}_{4}\right)_{22} \mathrm{HC}_{6} \mathrm{H}_{5} \mathrm{O}_{7}\left(0,006 \mathrm{~g} . \mathrm{L}^{-1}\right)$ (RIPPKA et al., 1979).

A concentração celular na fase exponencial para tomada dos inóculos foi determinada gravimetricamente mediante filtração de volume conhecido de meio de cultura BG-11 contendo as células do micro-organismo. A cultura foi filtrada em filtro Millipore $(0,45 \mu \mathrm{m})$, previamente seco a 60 으. Os filtros foram secos até peso constante e a biomassa quantificada.

\section{Planejamento Experimental}

Os experimentos foram conduzidos de acordo com um delineamento fatorial completo $3^{2}$ frente às variáveis razão $\mathrm{C} / \mathrm{N}$ e N/P, nos níveis 20,40 e 60 e 5, 10 e 15, respectivamente. Os níveis das variáveis independentes foram ajustados, tomando como base as razões $\mathrm{C} / \mathrm{N}$ e N/P do efluente obtidas a partir da determinação de DQO e N-NTK. A razão C/N foi ajustada com glicose e a N/P com fosfato dissódico. Os experimentos foram realizados em triplicata, as variáveis e níveis utilizados, estão apresentados na Tabela 1.

Tabela 1: Matriz do planejamento experimental.

\begin{tabular}{|l|l|l|}
\hline Tratamento & \multicolumn{1}{c|}{\begin{tabular}{c}
\multicolumn{1}{c|}{$\mathrm{X}_{2}$} \\
\hline 1
\end{tabular} $\mathrm{X}_{1}$} & $-1(5)$ \\
\hline 2 & $-1(20)$ & $0(10)$ \\
\hline 3 & $-1(20)$ & $+1(15)$ \\
\hline 4 & $-1(20)$ & $-1(5)$ \\
\hline 5 & $0(40)$ & $0(10)$ \\
\hline 6 & $0(40)$ & $+1(15)$ \\
\hline 7 & $0(40)$ & $-1(5)$ \\
\hline 8 & $+1(60)$ & $0(10)$ \\
\hline 9 & $+1(60)$ & $+1(15)$ \\
\hline
\end{tabular}

$\mathrm{X}_{1}$ : razão $\mathrm{C} / \mathrm{N} ; \mathrm{X}_{2}$ : razão $\mathrm{N} / \mathrm{P}$

De acordo com as respostas do planejamento experimental, os efeitos de cada variável foram calculados e as interações entre eles determinadas. As superfícies de resposta foram obtidas através da montagem dos modelos empíricos (Equação 1).

$$
Y=\beta_{0}+\beta_{1} X_{1}+\beta_{2} X_{2}+\beta_{11} X_{1}^{2}+\beta_{22} X_{2}^{2}+\beta_{12} X_{1} X_{2}
$$

Onde: $X_{1}$ e $X_{2}$ são os níveis codificados das variáveis independentes; $\beta$ é o coeficiente de regressão; $\beta_{0}$ : intercepção; $\beta_{1}$ e $\beta_{2}$ : linear; $\beta_{12}$ : interação e $\beta_{11}, \beta_{22}$ : coeficientes quadráticos e $Y$ é a resposta predita para a variável dependente.

\section{Desenvolvimento dos experimentos}

Experimentos em triplicata na ausência de luz, de acordo com o planejamento experimental (Tabela 1) foram conduzidos, em biorreator tipo coluna de bolhas em sistema descontínuo com capacidade de $4,5 \mathrm{~L}$, constituído de uma extensão cilíndrica de PVC com dimensões de $100 \mathrm{~cm}$ de altura e $10 \mathrm{~cm}$ de diâmetro. $O$ 
sistema de dispersão de gases do reator consistiu em um difusor de ar de 1,5 cm localizado no centro da base da coluna para promover a aeração e agitação do meio. A cada experimento, o efluente da indústria de laticínio foi descongelado e então esterilizado a 1,1 kgf.cm $\left(120^{\circ} \mathrm{C}\right)$ por 15 minutos, para a realização dos experimentos. Os experimentos foram conduzidos com controle de temperatura através do uso de termômetro da marca INCOTERM. No efluente previamente ajustado a $\mathrm{pH} 7,6$ e quanto às razões $\mathrm{C} / \mathrm{N}$ e N/P, $200 \mathrm{mg} \cdot \mathrm{L}^{-1}$ de células de Aphanothece microscópica Nägeli, na fase exponencial de crescimento foram inoculadas a $30^{\circ} \mathrm{C}$. Os experimentos foram monitorados, mediante tomada de amostras a intervalos de $2 \mathrm{em}$ $2 \mathrm{~h}$, filtrados em filtro Millipore $(0,45 \mu \mathrm{m})$ e a biomassa gravimetricamente determinada, para levantamento dos dados cinéticos.

\section{Cinética do Crescimento Celular}

As variáveis cinéticas, a velocidade específica de crescimento máxima $\left(\mu_{\text {máx }}\right)$, o tempo de geração $(\operatorname{tg})$ e o fator de conversão de substrato em células $\left(\mathrm{Y}_{\mathrm{x} / \mathrm{s}}\right)$, foram determinadas conforme indicado por Levenspiel (2000). O procedimento de avaliação teve como base as equações 2, 3, 4, 5 e 6.

$$
\frac{d X}{d t}=\mu X
$$

Onde: $\mu$ máx é a velocidade específica de crescimento do micro-organismo $\left(\mathrm{h}^{-1}\right)$; $\mathrm{dX}$ é a variação da concentração celular $\left(m g . L^{-1}\right) ; d t$ é a variação do tempo $(\mathrm{h}) ; \mathrm{X}$ é a concentração celular $\left(\mathrm{mg} \cdot \mathrm{L}^{-1}\right)$. Integrando-se a equação 2 obtém-se a equação 3 .

$$
X=X_{0} e^{\mu_{\max }(\Delta t)}
$$

Onde: $X$ é a concentração celular no final da fase exponencial $\left(m g . L^{-1}\right) ; X_{o}$ é a concentração celular no início da fase

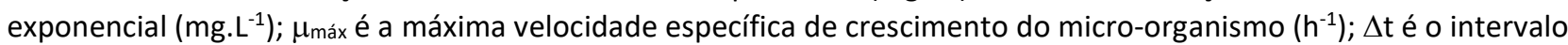

$$
\operatorname{tg}=\frac{\ln 2}{\mu_{\max }}
$$
de tempo do crescimento exponencial $(h)$.

$$
Y_{X / S}=-\frac{d X}{d S}
$$

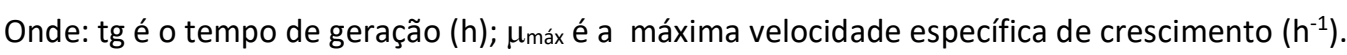

Onde: $\mathrm{Y}_{\mathrm{x} / \mathrm{s}}$ é o fator de conversão substrato em células ( $\mathrm{mg}$ biomassa. $\left.\mathrm{mg} \cdot \mathrm{S}^{-1}\right)$; $\mathrm{dX}$ é a variação da concentração celular

$$
P_{X}=\frac{\Delta X}{\Delta t}
$$
$\left(\mathrm{mg} \cdot \mathrm{L}^{-1}\right) ; \mathrm{dS}$ é a variação do substrato $\left(\mathrm{mg} \cdot \mathrm{L}^{-1}\right)$.

Onde: Px é a produtividade $\left(m g \cdot L^{-1} h^{-1}\right) ; \Delta X$ é a variação da concentração final e inicial $\left(m g \cdot L^{-1}\right) ; \Delta t$ é a variação entre o tempo final e inicial (h).

\section{Análise dos dados}

O modelo (regressão) gerado, conforme Equação 1, foi avaliado por meio de análise de variância (ANOVA) e sua validade ou grau de ajuste determinado por meio de teste $F$, que consiste em relacionar o valor de $\mathrm{F}$ calculado $\left(\mathrm{F}_{\text {calc }}\right)$ com o valor de $\mathrm{F}_{\text {tabelado }}\left(\mathrm{F}_{\mathrm{Tab}}\right)$, se o valor de $\mathrm{F}_{\text {calc }}$ pela ANOVA for maior que o $\mathrm{F}_{\text {Tab, a }}$ regressão obtida ajusta os pontos experimentais de forma satisfatória, validando o modelo no intervalo de confiança estudado (MYERS et al., 2002). 


\section{RESULTADOS E DISCUSSÃO}

A Tabela 2 apresenta a caracterização do efluente de leite utilizado com as respectivas médias e coeficientes de variação (CV) calculadas para a demanda química de oxigênio (DQO), nitrogênio total ( $N$ NTK), fósforo total $\left(P-\mathrm{PO}_{4}^{-3}\right)$, razão carbono nitrogênio $(\mathrm{C} / \mathrm{N})$ e razão nitrogênio e fósforo (N/P). A utilização de água pela indústria de laticínios ocorre principalmente em processos de limpezas como lavagem de tubulações, pisos, tanques e demais equipamentos, gerando quantidades significativas de efluentes líquidos com elevada carga orgânica e acentuado teor de nitrogênio e fósforo (VILLA et al., 2007; WANG et al., 2005). Por isso, todos os parâmetros físico-químicos mostraram uma alta variabilidade, confirmando a heterogeneidade do efluente avaliado. Somente no Brasil são gerados $84 \times 10^{9} \mathrm{~L}$ de efluentes oriundos de industrias lácteas (CAMMAROTA et al., 2006), variando na faixa de 1195 a $5000 \mathrm{mg}^{-1}$ de DQO, N-NTK entre

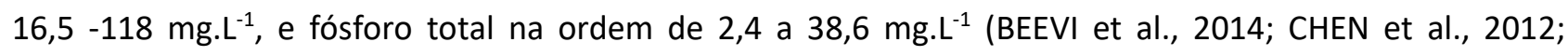
KUSHWAHA et al., 2010).

Tabela 2: Caracterização do efluente de laticínios.

\begin{tabular}{|l|l|l|}
\hline Parâmetros & Média & CV \\
\hline DQO & 950 & 40,3 \\
\hline N-NTK & 42,2 & 35,13 \\
\hline P-PO4-3 & 4,5 & 22,1 \\
\hline C/N & 22,09 & 6,42 \\
\hline N/P & 9,7 & 13,6 \\
\hline
\end{tabular}

DQO: demanda química de oxigênio; N-NTK: nitrogênio total Kjeldahl;

$\mathrm{P}-\mathrm{PO}_{4}^{-3}$ : fósforo total; $\mathrm{C} / \mathrm{N}$ : razão carbono/nitrogênio; N/P: nitrogênio/fosforo;

$\mathrm{CV}$ : coeficiente de variação. Unidades em mg. $\mathrm{L}^{-1}$.

Os valores de DQO, N-NTK e P-PO ${ }^{-3}$ do efluente da indústria de laticínios são semelhantes aos encontrados na literatura (ZHU et al., 2013), que por ser substancialmente elevado existe o interesse de aplicar o tratamento biológico assim como em águas residuárias do processamento do pescado e parboilização do arroz (HORNES et al., 2010; QUEIROZ et al., 2007).

A Tabela 2 mostra que a razão $\mathrm{C} / \mathrm{N}$ é de 22,09 e a N/P de 9,7, próxima a requerida para o desenvolvimento das cianobactérias ( $C / N=20, N / P=10$ a 16) conforme citado por Pearson (1990). Diante disso, o efluente de leite apresenta potencialidade de suportar o cultivo destes microrganismos (QUEIROZ et al., 2007; PEARSON et al., 1990). O comportamento de crescimento da Aphanothece microscópica Nägeli desenvolvida no efluente da indústria de leite para as diferentes condições experimentais pode ser avaliado nas Figuras 1 a 9.

A análise dos perfis de crescimento demonstra a influência das razões $C / N$ e N/P, na produção celular. Observa-se diferenças notórias no período de duração principalmente no que se refere a fase logarítmica. Estas diferenças são melhor avaliadas em função dos modelos de definição das fases logarítmicas de crescimento (Tabela 3), obtidos a partir dos modelos de crescimento (Tabela 4), preditos para cada experimento, onde são registrados importantes valores de coeficiente de determinação $(0,96$ a 0,99$)$ demonstrando o bom ajuste dos modelos. Verifica-se, pela análise da Tabela 3, intensas variações no tempo de duração das fases logarítmicas descritas, variando de 12 a 20 h. O maior período registrado (20 h) corresponde ao experimento 7 (Figura 7), quando são utilizadas razões C/N 60 e N/P 5. 


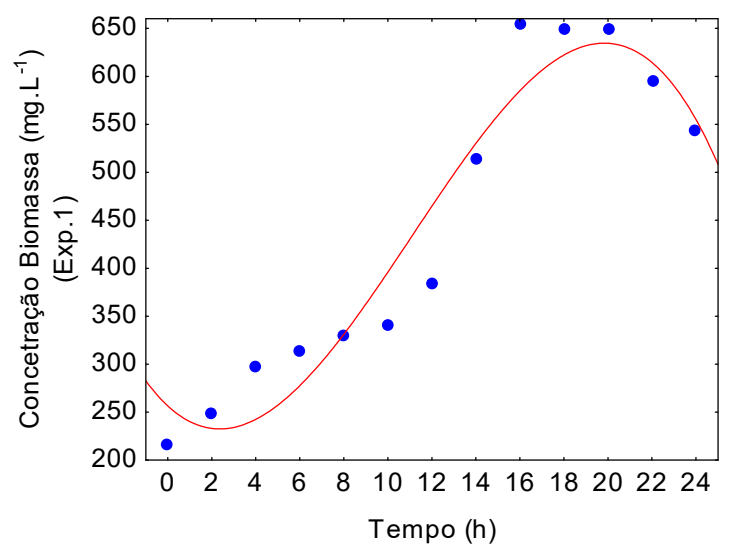

Figura 1: Curva de crescimento para Aphanothece microscópica Nägeli cultivada no efluente de laticínios sob as condições do experimento 1 (C/N 20; N/P 5)

(valores médios de 3 repetições).

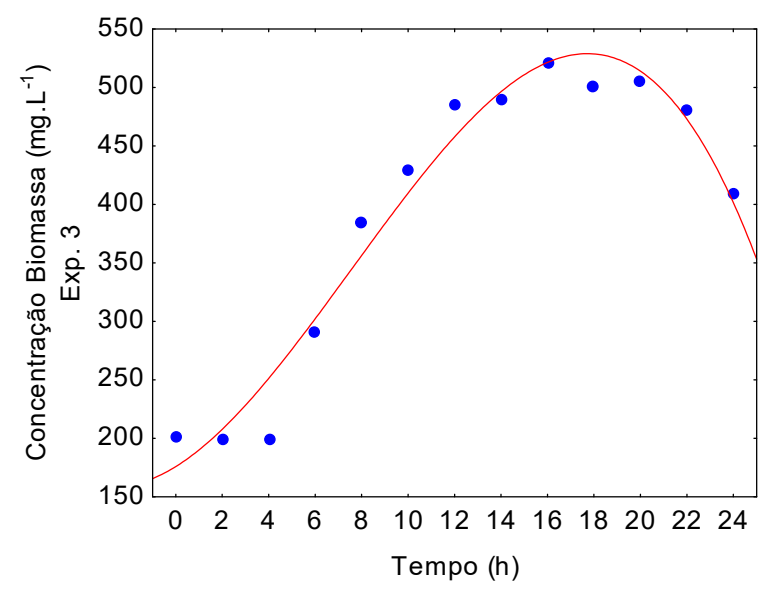

Figura 3: Curva de crescimento para Aphanothece microscópica Nägeli cultivada no efluente de laticínios sob as condições do experimento 3 (C/N 20; N/P 15) (valores médios de 3 repetições, $n=3$ ).

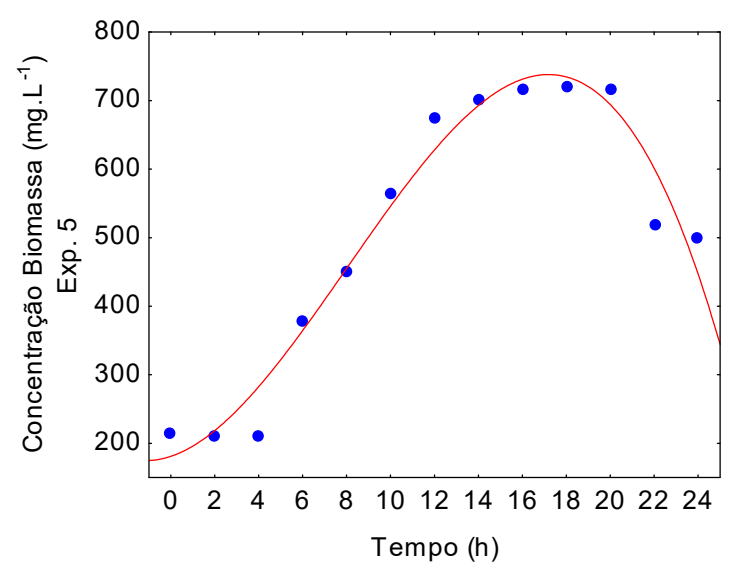

Figura 5:Curva de crescimento para Aphanothece microscópica Nägeli cultivada no efluente de laticínios sob as condições do experimento 5 (C/N 40; N/P 10)

(valores médios de 3 repetições, $n=3$ ).

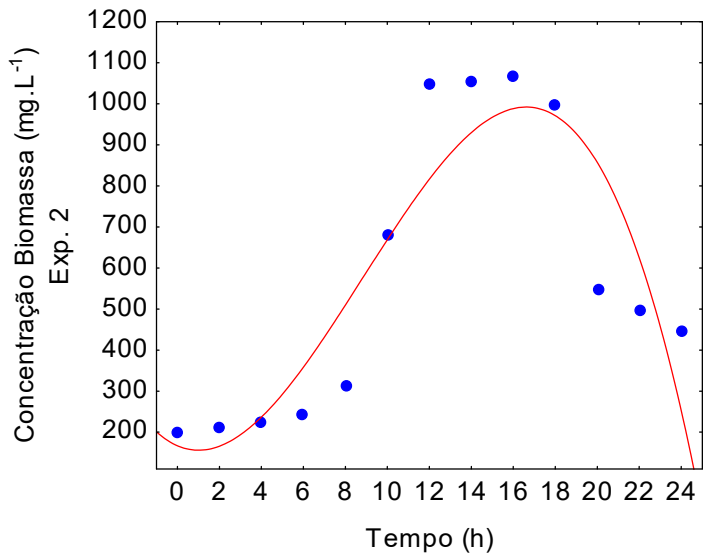

Figura 2: Curva de crescimento para Aphanothece microscópica Nägeli cultivada no efluente de laticínios sob as condições do experimento 2 (C/N 20; N/P 10)

(valores médios de 3 repetições, $n=3$ ).

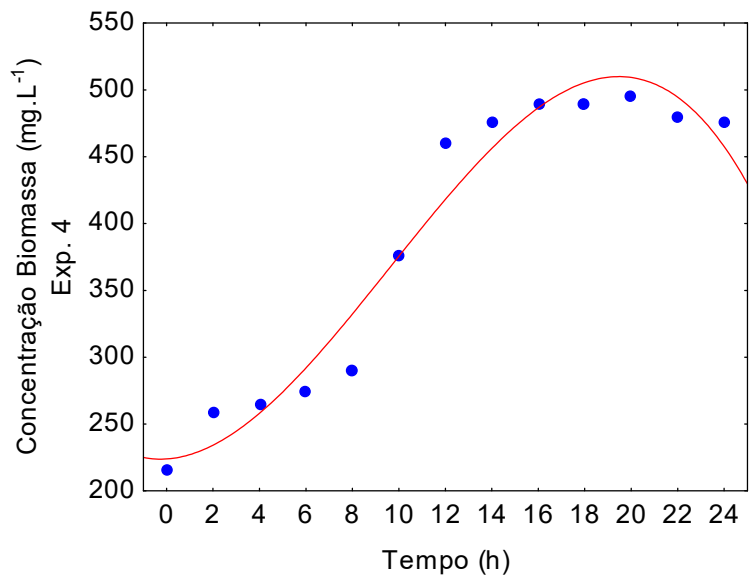

Figura 4: Curva de crescimento para Aphanothece microscópica Nägeli cultivada no efluente de laticínios sob as condições do experimento 4 (C/N 40; N/P 5)

(valores médios de 3 repetições, $n=3$ ).

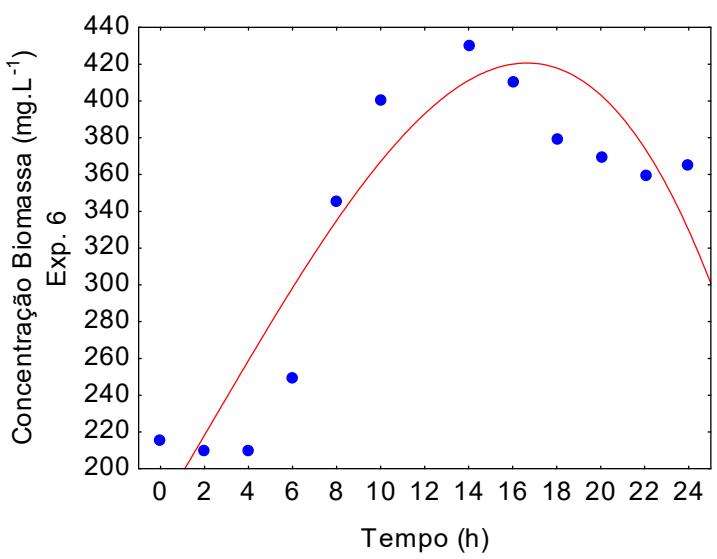

Figura 6: Curva de crescimento para Aphanothece microscópica Nägeli cultivada no efluente de laticínios sob as condições do experimento 6 (C/N 40; N/P 15)

(valores médios de 3 repetições, $n=3$ ). 


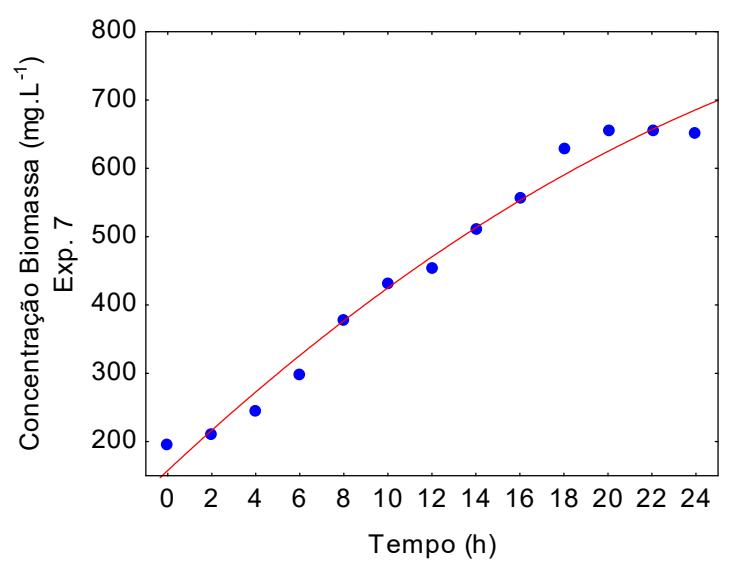

Figura 7: Curva de crescimento para Aphanothece microscópica Nägeli cultivada no efluente de laticínios sob as condições do experimento 7 (C/N 60; N/P 5) (valores médios de 3 repetições, $n=3$ ).

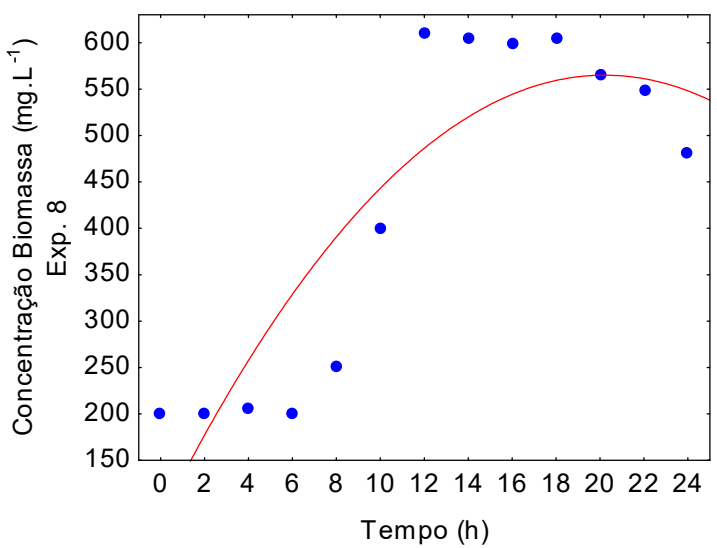

Figura 8: Curva de crescimento para Aphanothece microscópica Nägeli cultivada no efluente de laticínios sob as condições do experimento 8 (C/N 60; N/P 10) (valores médios de 3 repetições, $n=3$ ).

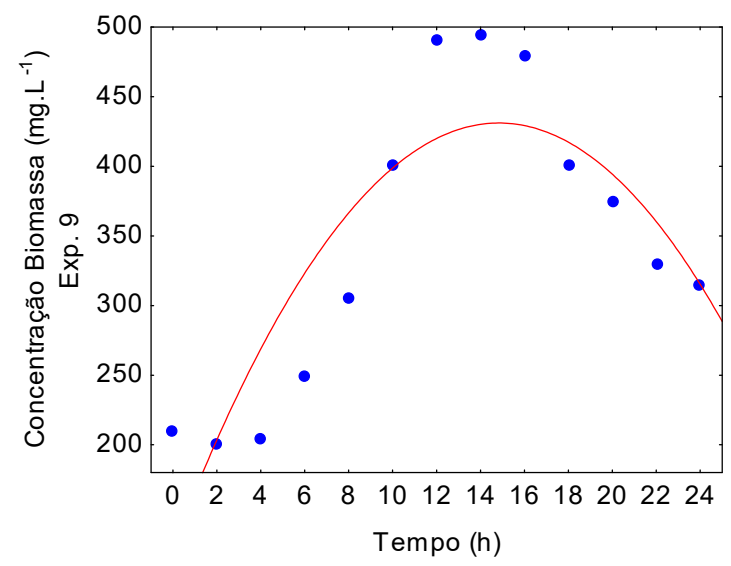

Figura 9: Curva de crescimento para Aphanothece microscópica Nägeli cultivada no efluente de laticínios sob as condições do experimento 9 (C/N 60; N/P 15) (valores médios de 3 repetições, $n=3$ ).

Tabela 3: Modelos de definição da fase logarítmica de crescimento celular de Aphanothece microscópica Nägeli.

\begin{tabular}{|l|l|l|l|}
\hline Experimentos & Modelos & $\mathrm{t}$ fase log & $\mathrm{R}^{2}$ \\
\hline 1 (C/N 20; N/P 5) & $\mathrm{y}=-225+53,75 . x$ & 16 & 0,97 \\
\hline 2 (C/N 20; N/P 10) & $\mathrm{y}=-670,7+138,05 . x$ & 12 & 0,96 \\
\hline 3 (C/N 20; N/P 15) & $\mathrm{y}=258,25+16,5 . x$ & 16 & 0,99 \\
\hline 4 (C/N 40; N/P 5) & $y=180+20 . x$ & 16 & 0,96 \\
\hline 5 (C/N 40; N/P10) & $y=121,5+43,25 . x$ & 16 & 0,97 \\
\hline 6 (C/N 40; N/P 15) & $y=55,5+34,25 . x$ & 12 & 0,98 \\
\hline 7 (C/N 60; N/P 5) & $y=167,08+24,79 . x$ & 20 & 0,98 \\
\hline 8 (C/N 60; N/P 10) & $y=-480+90 . x$ & 12 & 0,99 \\
\hline 9 (C/N 60; N/P 15) & $y=-5,5+40,75 . x$ & 12 & 0,98 \\
\hline
\end{tabular}

y: concentração celular (mg. $\left.\mathrm{L}^{-1}\right)$; $x$ : tempo de cultivo (h); t fase log: tempo de duração da fase logarítmica de crescimento celular (h); $\mathrm{R}^{2}$ : coeficiente de determinação.

Tabela 4. Modelos de crescimento de Aphanothece microscópica Nägeli de acordo com os experimentos.

\begin{tabular}{|c|c|c|}
\hline Experimentos & Modelos & $R^{2}$ \\
\hline 1 (C/N 20; N/P 5) & Biomassa $=(256,514)+(-21,154) t+(5,01617) t^{2}+(-0,15068) t^{3}$ & 0,97 \\
\hline 2 (C/N 20; N/P 10) & Biomassa $=(166,844)+(-21,99) t+(11,6195) t^{2}+(-0,43972) t^{3}$ & 0,94 \\
\hline 3 (C/N 20; N/P 15) & Biomassa $=(175,948)+(12,318) t+(1,9827) t^{2}+(-0,08767) t^{3}$ & 0,98 \\
\hline $4(\mathrm{C} / \mathrm{N} 40 ; \mathrm{N} / \mathrm{P} 5)$ & Biomassa $=(223,918)+(1,15092) t+(2,14636) t^{2}+(-0,07452) t^{3}$ & 0,98 \\
\hline 5 (C/N 40; N/P 10) & Biomassa $=(180,978)+(10,7077) t+(4,40772) t^{2}+(-0,18298) t^{3}$ & 0,98 \\
\hline 6 (C/N 40; N/P 15) & Biomassa $=(177,953)+(19,8138) t+(0,246315) t^{2}+(-0,03369) t^{3}$ & 0,90 \\
\hline 7 (C/N 60; N/P 5) & Biomassa $=(6,60572)+(30,0854) t+(-0,33666) t^{2}+(5,327) t^{3}$ & 0,90 \\
\hline $8(\mathrm{C} / \mathrm{N} 60 ; \mathrm{N} / \mathrm{P} 10)$ & Biomassa $=(-61,649)+(47,2735) t+(-1,1697) t^{2}+(5,30163) t^{3}$ & 0,90 \\
\hline 9 (C/N 60; N/P 15) & Biomassa $=(-6,1995)+(40,9753) t+(-1,3805) t^{2}+(5,10821) t^{3}$ & 0,90 \\
\hline
\end{tabular}

$\mathrm{T}$ : tempo de cultivo (h); Biomassa (mg. $\left.\mathrm{L}^{-1}\right) ; \mathrm{R}^{2}$ : coeficiente de determinação. 
A cinética da Aphanothece microscópica Nägeli cultivada no efluente da indústria de laticínios sob as condições experimentais, pode ser avaliada na Tabela 5. São apresentados os parâmetros clássicos de cinética de crescimento, expressos como máxima velocidade de crescimento ( $\left.\mu_{\text {máx }}\right)$, tempo de geração (tg), produtividade de biomassa $\left(P_{x}\right)$ e de conversão de substrato em células $\left(Y_{s / x}\right)$ com base no consumo de nitrogênio e matéria orgânica.

Tabela 5: Parâmetros Cinéticos.

\begin{tabular}{|c|c|c|c|c|c|c|c|c|c|}
\hline \multirow[t]{2}{*}{ Variáveis cinéticas } & \multicolumn{9}{|c|}{ Condições experimentais } \\
\hline & 1 & 2 & 3 & 4 & 5 & 6 & 7 & 8 & 9 \\
\hline$\Delta \mathrm{t}(\mathrm{h})$ & 6 & 6 & 8 & 6 & 8 & 6 & 13 & 4 & 6 \\
\hline $\mathrm{X}$ & 655 & 1025 & 520 & 490 & 700 & 460 & 655 & 610 & 490 \\
\hline$x_{0}$ & 340 & 225 & 385 & 375 & 380 & 250 & 300 & 250 & 250 \\
\hline$\mu_{\text {máx. }}$ & 0,113 & 0,25 & 0,0366 & 0,0467 & 0,0814 & 0,0989 & 0,0528 & 0,223 & 0,1145 \\
\hline tg & 6,14 & 2,77 & 18,94 & 14,84 & 8,51 & 7 & 13,13 & 3,1 & 6,05 \\
\hline$Y_{X / S \text { DQO }}$ & 0,43 & 0,55 & 0,56 & 0,18 & 0,75 & 0,78 & 0,17 & 0,23 & 0,17 \\
\hline $\mathrm{Y}_{\mathrm{X} / \mathrm{S} \text { N-NTK }}$ & 9,35 & 15,53 & 6,1 & 5,22 & 14,54 & 17,07 & 2,83 & 11,51 & 20,03 \\
\hline $\mathrm{YX}_{\mathrm{X} / \mathrm{SP}_{-} \mathrm{PO4}^{-3}}$ & 109 & 38,47 & 43,97 & 29,64 & 103,22 & 170,73 & 76,67 & 173,07 & 105,72 \\
\hline$P_{x}$ & 52,5 & 136,67 & 16,87 & 19,16 & 40 & 35 & 27,3 & 90 & 40 \\
\hline
\end{tabular}

$\Delta \mathrm{t}$ : Intervalo de tempo da fase exponencial de crescimento; $\mathrm{X}$ : Concentração celular final $\left(\mathrm{mg} . \mathrm{L}^{-1}\right) ; \mathrm{X}_{0}$ : Concentração celular Inicial (mg. $\left.L^{-1}\right) ; \mu_{\text {máx: }}$ Máxima velocidade específica de crescimento $\left(\mathrm{h}^{-1}\right)$; tg: Tempo de geração $(\mathrm{h}) ; \mathrm{Y}_{\mathrm{x} / \mathrm{s}}$ : Conversão de substrato em biomassa ( $\left.\mathrm{mg}_{\text {biomassa. }} \mathrm{mg}\right)$; $\mathrm{P}_{\mathrm{x}}$ : produtividade de biomassa $\left(\mathrm{mg} \cdot \mathrm{L}^{-1} \cdot \mathrm{h}^{-1}\right)$.

A análise dos dados da Tabela 5 demonstram, que o maior potencial de cultivo foi quando utilizouse a condição 2 (C/N 20, N/P 10), potencial este expresso por uma concentração celular máxima de 1045 mg. $\mathrm{L}^{-1}$, velocidade máxima específica de crescimento de $0,250 \mathrm{~h}^{-1}$, tempo de geração correspondendo a $2,77 \mathrm{~h}$ e importante valor de tempo de batelada para atingir a máxima concentração celular de $6 \mathrm{~h}$. Estes valores são notadamente diferenciados de qualquer outra condição estudada, no que se refere a produção de biomassa.

A literatura é ampla quanto a robustez metabólica das microalgas, refletindo em mínimas exigências nutricionais, desta forma podendo os cultivos heterotróficos ser suportados por águas residuárias de inúmeros processos industriais (BASTOS et al., 2010; DEVI et al., 2012; GUERRERO, 1999; HARUM et al., 2010; QUEIROZ et al., 2007; OGBOONA et al., 2000; TAM et al., 2000; WANG et al., 2005).

É importante salientar, que o efluente, utilizado no experimento 2, não sofreu ajuste das razões $\mathrm{C} / \mathrm{N}$ e N/P, conforme se pode avaliar pelos dados da Tabela 2, que fornecem as características do efluente bruto, utilizado para o desenvolvimento dos experimentos. Isso faz do efluente da indústria de laticínio um excelente meio de cultivo.

O elevado valor obtido para o coeficiente de conversão de matéria orgânica em biomassa, para o experimento 2 indica que as formas carbonadas presentes neste efluente, são mais facilmente bioconvertidas, o que sugere alto consumo de substrato, com baixa conversão em biomassa. De acordo com Perez-Garcia et al. (2011), ao mesmo tempo em que diversas fontes de carbono têm sido propostas para os cultivos heterotróficos de microalgas, poucos substratos, são passíveis de uso pelos micro-organismos. As fontes de carbono frequentemente utilizadas para esta categoria de cultivos tem sido a glicose, acetato e glicerol (HEREDIA-ARROYO et al., 2010; PEREZ-GARCIA et al., 2011). 
Janczukowicz et al. (2008), reportam a alta biodegradação de lactose a acetato, bem como de gorduras a glicerol, no efluente de laticínio. Os dados da Tabela 5 evidenciam influência notória das razões $\mathrm{C} / \mathrm{N}$ e N/P no crescimento celular, com significativas reduções à medida que aumenta a razão $\mathrm{C} / \mathrm{N}$, e com as variações de N/P. Este fato se reflete no fator de conversão de nitrogênio em células, que com o aumento das razões $\mathrm{C} / \mathrm{N}$, embora os valores dos coeficientes de conversão de nitrogênio em células se reduzem em relação ao valor obtido para o experimento 2 , maiores valores são registrados, para as maiores razões N/P. Este comportamento pode ser atribuído a natureza do nitrogênio disponibilizado, mediante o ajuste das concentrações $\mathrm{C} / \mathrm{N}$ e N/P, caracterizando-se pela presença substancial em nitrogênio amoniacal, quando comparada ao experimento 2 , forma nitrogenada está de destaque, quando se aborda o tema inibição do crescimento microalgal (PRZYTOCKA-JUSIAK, 1976).

A fonte e a qualidade da fonte nitrogenada são fatores que afetam significativamente o crescimento celular (LEE et al., 2007). Por outro lado, a quantidade da relação $\mathrm{C} / \mathrm{N}$ também influencia no crescimento de cianobactérias e na composição da biomassa gerada no processo. Na literatura, observamos que quando utilizamos relação $\mathrm{C} / \mathrm{N}$ reduzidas, a biomassa originada é rica em proteínas, enquanto que, o aumento desta relação, possibilita uma biomassa rica em carboidratos e lipídicos (PEREZ-GARCIA et al., 2011; SILVAMANETTI, 2013)

No entanto, considerando as velocidades específicas máximas de crescimento, é possível constatar que todos os experimentos apresentaram potencial para a produção de biomassa. Se considerarmos as velocidades de formação de biomassa como parâmetro base, verifica-se que o menor valor obtido (0,0366 $\mathrm{h}^{-}$ $\left.{ }^{1}\right)$, registrado para o experimento 3, é comparável a cultivos fotossintéticos $\left(0,038 \mathrm{~h}^{-1}\right)$, para o microorganismo em estudo, em condições otimizadas segundo Jacob-Lopes et al. (2008). Este valor 0,0366 $\mathrm{h}^{-1}$, é em torno de 3 vezes maiores ao registrado para outras espécies em cultivo fotossintético (CHAE et al., 2006; YUE et al., 2005).

\section{CONCLUSÕES}

As variáveis cinéticas de crescimento revelam a possibilidade da aplicação da Aphanothece no efluente de laticínios na ausência de luminosidade, obtendo-se, dessa forma, elevadas concentrações de células em 24 horas de cultivo. No que se refere a fase exponencial de crescimento de Aphanothece microscópica Nägeli cultivada no efluente do leite, foi registrado a partir de $4 \mathrm{~h}$, com velocidades especificas de crescimento máxima de $0,2230 \mathrm{~h}^{-1}$ (Experimento 8) e mínimas de $0,0366 \mathrm{~h}^{-1}$ (Experimento 3) com tempo de geração 18,94 e 3,10h, respectivamente. Estes resultados revelam a possibilidade de produção de biomassa e uso do efluente como meio de cultivo a partir da Aphanothece em condições heterotróficas, na ausência de luminosidade. Nas condições experimentais, para os experimentos com relação C/N 20 e N/P 10 foram registradas eficiências de remoção de DQO, N-NTK e fósforo total de 94,70, 83,33 e 66,66 \%, respectivamente. Em relação as variáveis cinéticas, foi obtido para o experimento 2, concentração celular máxima de $1045 \mathrm{mg} \cdot \mathrm{L}^{-1}$, velocidade máxima específica de crescimento de $0,250 \mathrm{~h}^{-1}$, tempo de geração de 2,77 h e valor de tempo de batelada para atingir a máxima concentração celular de $6 \mathrm{~h}$, demonstrando que 
as razões $\mathrm{C} / \mathrm{N}$ e N/P exercem influência tanto no crescimento da Aphanothece como na eficiência de remoção

dos compostos.

\section{REFERÊNCIAS}

ANGELO, E. A.; ANDRADE, D. S.; COLOZZI FILHO, A.. Cultivo não-fotoautotrófico de microalgas: uma visão geral. Semina: Ciências Biológicas e da Saúde, v.35, n.2, p.125-136, 2015.

ANSILAGO, M.; OTTONELLI, F.; DE CARVALHO, E. M.. Cultivo da microalga Pseudokirchneriella subcapitata em escala de bancada utilizando meio contaminado com metais pesados. Engenharia Sanitária e Ambiental, v.21, n.3, p.603608, 2016.

\section{APHA. American Public Health Association. Standard} Methods for the Examination of Water and Wastewater. 20 ed. Washington: 2005.

BASTOS, R. G.; QUEIROZ, M. I.; ALMEIDA, T. L.; BENERI, R. L.; ALMEIDA, R. V.; PADILHA, M.. Remoção de nitrogênio e materia orgânica do efluente da parboilização do arroz por Aphanothece microscopica Nägeli na ausência de luminosidade. Revista da Engenharia Sanitária e Ambiental, v.9, n.2, p.112-116, 2004.

BASTOS, R. G.; SEVERO, M.; VOLPATO, G.; JACOB-LOPES, E.; ZEPKA, L. Q.; QUEIROZ, M. I.. Bioconversão do nitrogênio do efluente da parboilização do arroz por incorporação em biomassa da cianobactéria Aphanothece microscopica Nägeli. Revista Ambiente \& Água, v.5, n.3, p.258-264, 2010.

BASTOS, R. G.; BONINI, M. A.; ZEPKA, L. Q.; JACOB-LOPES, E.; QUEIROZ, M. I.. Treatment of rice parboiling wastewater by cyanobacterium Aphanothece microscopica Nägeli with potential for biomass products. Desalination and Water Treatment, v.56, n.3, p.608-614, 2015.

BASTOS, R. G.; BONINI, M. A.. Produção de biomassa de microalgas a partir de cultivo mixotrófico em acetato. Revista Ciência, Tecnologia \& Ambiente, v.4, n.1, p.38-44, 2017.

BEEVI, U. S.; SUKUMARAN, R. K.. Cultivation of microalgae in dairy efflu-ent for oil production and removal of organic pollution load. Bioresource Technology, v.165, p.295-301, 2014.

BONINI, M. A.; BASTOS, R. G.. Produção de biomassa de Aphanothece microscopica e Chlorella vulgaris por cultivo heterotrófico a partir de glicose. Semina: Ciências Biológicas e da Saúde, v.33, n.2, p.151-160, 2012.

CAI, T.; PARK, S. Y.; LI, Y.. Nutrient recovery from wastewater streams by microalgae: Status and prospects. Renewable and Sustainable Energy Reviews, v.19, p.360-369, 2013.

CAMMAROTA, M. C.; FREIRE D. M. G.. A review on hydrolytic enzymes in the treatment of wastewater with high oil and grease content. Bioresource Technology, v.97, n.17, p.21952210, 2006

CHAE, S. R.; HWANG, E. J.; SHIN, H. S.. Single cell protein production of Euglena gracilis and carbon dioxide fixation in an innovative photo-bioreactor. Bioresource Technology, v.97, p.322-329, 2006
CHEN, W.; LIU, J.. The possibility and applicability of coagulation-MBR hy-brid system in reclamation of dairy wastewater. Desalination, v.285, p.226-231, 2012.

HEREDIA-ARROYO, T.; WEI, W.; HU, B.. Oil accumulation via heterotrophic/mixotrophic Chlorella protothecoides. Applied biochemistry and biotechnology, v.162, n.7, p.1978-1995, 2010.

HOMIAK, J. A.. Produção de biodiesel utilizando microalgas. Revista de Saúde e Biologia, v.9, n.2, p.65-74, 2014.

HORNES, M.; QUEIROZ, M. I.. O Efeito da razão $\mathrm{C} / \mathrm{N}$ e do inóculo na remo-ção de nitrogênio do efluente da indústria da pesca pela cianobactéria. Revista Vetor, Rio Grande, v.15, n.1, p.25-32, 2005.

HORNES, M.; SILVA, A. G.; MITTERER, M. L.; QUEIROZ, M. I.. Influência dos compostos nitrogenados na concentração de proteína da cianobactéria Aphanothece microscópica Nägeli. Ciência e Tecnologia de Alimentos, v.30, n.2, p.364-371, 2010.

JACOB-LOPES, E.; SCOPARO, C. H. G.; FRANCO, T. T.. Rates of $\mathrm{CO}_{2}$ removal by Aphanothece microscopica Nägeli in tubular photobioreactors. Chemical Engineering and Processing, Lausanne, v.47, p.1365-1373, 2008.

JANCZUKOWICZ, W.; ZIELIN, S.; BOWSKI, M.. Biodegradability evaluation of dairy effluents originated in selected sections of dairy production. Bioresource Technology, v.99, p.4199-4205, 2008.

KUSHWAHA, J. P.; SRIVASTAVA, V.; MALL, I. D.. Treatment of dairy wastewater by commercial activated carbon and bagasse fly ash: arametric, kinetic and equilibrium modelling, disposal studies. Bioresource Technology, v.101, p.3474-3483, 2010.

LEE, W. Y.; PARK, Y.; AHN, J. K.; KA, K. H.; PARK, S. Y.. Factors influencing the production of endopolysaccharide and exopolysaccharide from Ganoderma applanatum. Enzyme and Microb. Technol., v.40, p.249-254, 2007.

LEVENSPIEL, O.. Engenharia das Reações Químicas. 3 ed. São Paulo: Edgard Blücher, 2000.

LI, Z.; YUAN, H.; YANG, J.; LI, B.. Optimization of the biomass production of oil algae Chlorella minutíssima UTEX2341. Bioresource Technology, v.102, p.9128- 9134, 2011.

LOPES, T. S. D. A.; SILVA, A. L. A.; SILVA, A. F.; DANTAS, G. D.; FER-REIRA, W. B.. Estudo do potencial de geração de biocombustíveis líquidos a partir de microalgas: Utilização de efluentes agroindustriais e domésticos no desenvolvimento da Chlorella. Revista Ciência e Tecnologia, v.18, n.33, p.2536, 2015.

MATA, T. M.; MARTINS, A. A.; CAETANO, N. S.. Microalgae for biodiesel production and others applications: a review. Renewable and Sustainable Energy Reviews, v.14, n.1, p.217-232, 2010 . 
MEDINA, G. I. L.; BONETT, J. E. A.; GELLVEZ, S. J. M.; PEÑALOZA, Y. A. M.; LIZARAZO, E. M. P.; SUÁREZ, N. A.. Producción de Ácidos Grasos Poliinsaturados a partir de Biomasa Microalgal en un Cultivo Heterotrófico. Revista ION, v.30, n.1, p.91-103, 2016.

MURO-PASTOR, M. I.; FLORENCIO, F. J.. Regulation of ammonium assimilation in cyanobacteria. Plant Physiology and Biochemistry, v.41, n.6-7, p.595-603, 2003.

MUTHURAJ, M.; KUMAR, V.; PALABHANVI, B.; DAS, D.. Evaluation of indigenous microalgal isolate Chlorella sp. FC2 IITG as a cell factory for biodiesel production and scale up in outdoor conditions. Journal of Industrial Microbiology \& Biotechnology, Heidelberg, v.41, n.3, p.499-511, 2014.

MYERS, R. H.; MONTGOMERY, D. C.. Response Surface Methodology. 2 ed. New York: Wiley \& Sons, 2002.

NOBRE, B. P.; VILLALOBOS, F.; BARRAGAN, B. E.; OLIVEIRA, A. C.; BATISTA, A. P.; MARQUES, P. A. S. S.; GOUVEIA, L.. Biorefinery from Nannochloropsis sp. microalga-Extraction of microalgal oils and pigments and biohydrogen production from biomass leftover. Bioresource Technology, v.135, p.128-36, 2013

PALABHANVI, B.; KUMAR, V.; MUTHURAJ, M.; DAS, D.. Preferential utilization of intracellular nutrients supports microalgal growth under nutrient starvation: multi-nutrient mechanistic model and experimental validation. Bioresource Technology, Essex, v.173, n.2, p.245-255, 2014.

PEREZ-GARCIA, O.; ESCALANTE, F. M. E.; DE-BASHAN, L. E.; BASHAN, Y.. Heterotrophic cultures of microalgae: metabolism and potential products. Water Research, Oxford, v.45, n.1, p.11-36, 2011.

PEARSON, M. J.. Toxic blue-green algae: Report of the National Rivers Authority Water Quality. United Kingdon: 1990.

PRZYTOCKA-JUSIAK, M.. Growth and Survival of Chlorella vulgaris in high concentrations of nitrogen. Actamicrobiol, v.25, p.287-289, 1976.

QUEIROZ, M. I.; BASTOS, R. G.; BENERI, R. L.; ALMEIDA, R. V.. Evaluación del crecimiento de la Aphanothece microscopica Nägeli en las aguas residuales de la parbolización del arroz. Información Tecnologica, v.13, n.1, p.61-65, 2002.

QUEIROZ, M. I.; ZEPKA, L. Q.; BASTOS, R. G.. Evaluation of single cell protein production by Aphanothece microscopica Nägeli in batch reactor. Food Science and Biotechnology, v.13, n.3, p.130-141, 2004.

QUEIROZ, M. I.; JACOB, E.; ZEPKA, L. Q.; BASTOS, R.. The kinetics of the removal of nitrogen and organic matter from parboiled rice effluent by cyanobacteria in a stirred batch reactor. Bioresource Technology, v.98, n.11, p.2163-2169, 2007.

QUEIROZ, M. I.; HORNES M. O.; SILVA-MANETTI, A. G.; JACOB-LOPES, E.. Single-cell oil production by cyanobacterium Aphanothece microscopica Nägeli 57 cultivated heterotrophically in fish processing wastewater. Applied Energy, v.88, p.3438-3443, 2011.

RAJOKA, M. I.; KHAN, S. H.; JABBAR, M. A.; AWAN, M. S.; HASHMI, A. S.. Kinetics of batch single cell protein production from rice polishings with Candida utilis in continuously aerated tank reactors. Bioresource technology, v.97, n.15, p.1934-1941, 2006.

RIPPKA, R.; DERUELLES, J.; WATERBURY, J. B.; HERDMAN, M.; STANIER, R. Y.. Generic assignments strain histories and properties of pure cultures of cyanobacteria. Journal of General Microbiology, v.111, p.1-61, 1979.

STREIT, N. M.; RAMÍREZ-MÉRIDA, L. G.; QUEIROZ ZEPKA, L.; JACOB-LOPES, E.; QUEIROZ, M. I.. Producción de pigmentos por Aphanothece microscópica Nageli a partir de residuos industriales lácteos. Ingeniare. Revista chilena de ingeniería, v.25, n.2, p.350-358, 2017.

STREIT, N.; MÉRIDA, L. G. R.; ZEPKA, L. Q.; JACOB-LOPES, E.; QUEIROZ, M.. Producción de pigmentos naturales (clorofilaa) en biorrefinerias agroindustriales Producing natural pigments (chlorophyll-a) in agroindustrial bio-refineries. Ciencia y Tecnología, v.8, n.2, p.29-36, 2015.

VIEIRA, J. G.; JACOB-LOPES, E.; MANETTI, A. G. S.; QUEIROZ, M. I.. Influência da temperatura na remoção de fosfato por microalgas em biorreatores heterotróficos. Ambiente \& Água, v.7, n.2, p.101-109, 2012.

VILLA, R. D.; SILVA, M. R.; NOGUEIRA, R. F. P.. Potencial de aplicação do processo foto-fenton/solar como prétratamento de efluente da indústria de laticínios. Química Nova, v.30, n.8, p.1799-1803, 2007.

WANG, Y.; HUANG, X.; YUAN, Q.. Nitrogen and carbon removals from food processing wastewater by an anoxic/aerobic membrane bioreactor. Process Biochemistry, v.40, p.1733-1739, 2005.

XIN, L.; HONG-YING, H.; YING-XUE, S.. Effects of different nitrogen and phosphorus concentrations on the growth, nutrient uptake, and lipid accumulation of a freshwater microalga Scenedesmus sp. Bioresource Technology, v.101, p.5494-5500, 2010.

YUE, L.; CHEN, W.. Isolation and determination of cultural characteristics of a new highly $\mathrm{CO} 2$ tolerant fresh water microalgae. Energy Conversion and Management, v.46, p.189-1846, 2005.

ZEPKA, L. Q.; JACOB-LOPES, E.; GOLDBECK, R.; SOUSASOARES, L. A.; QUEIROZ, M. I.. Nutritional evaluation of single-cell protein produced by Aphanothece microscopica Nägeli. Bioresource Technology, v.101, n.18, p.7118-7122, 2010.

ZHU, J.; RONG, J.; ZONG, B.. Factors in mass cultivation of microalgae for biodiesel. Chinese Journal of Catalysis, v.34, p.80-100, 2013.

A CBPC - Companhia Brasileira de Produção Científica (CNPJ: 11.221.422/0001-03) detém os direitos materiais desta publicação. Os direitos referem-se à publicação do trabalho em qualquer parte do mundo, incluindo os direitos às renovações, expansões e disseminações da contribuição, bem como outros direitos subsidiários. Todos os trabalhos publicados eletronicamente poderão posteriormente ser publicados em coletâneas impressas sob coordenação da Sustenere Publishing, da Companhia Brasileira de Produção Científica e seus parceiros autorizados. Os (as) autores (as)

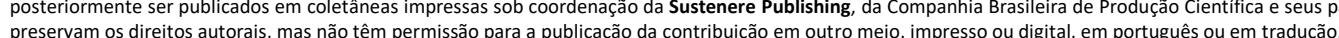

